\title{
Evolutionary de Winter pattern: from de Winter ECG to STEMI-A case report
}

\author{
Hao Wang ${ }^{1 *}$ (D, Xiao-Ce Dai ${ }^{2}$, Yun-Tao Zhao ${ }^{3}$ and Xiao-Hang Cheng ${ }^{1}$
}

\begin{abstract}
Background: De Winter pattern is associated with acute occlusion in the left anterior descending coronary artery combined with upsloping ST-segment depression at the J point in leads $V_{1}$ through $V_{6}$ without ST-segment elevation. The ECG changes in this case were illustrated by an up-sloping ST-segment depression in the $V_{1}$ to $V_{6}$ leads, followed by tall and symmetrical T waves. Changes from de Winter to ST-segment elevation myocardial infarction (STEMI) are rare.
\end{abstract}

Case presentation: Our case illustrated an evolutionary de Winter sign that changed to STEMI; the patient underwent cardiac catheterization in time.

Conclusions: Patients who have an electrocardiogram showing de Winter changes may require primary percutaneous coronary intervention. Emergency physicians and cardiologists should not ignore these changes.

Keywords: Cardiac anatomy, Noninvasive, Case report

\section{Background}

Acute subtotal or total proximal left anterior descending (LAD) occlusion can present de Winter ST-T changes. The main characteristics of the de Winter electrocardiogram (ECG) pattern are up-sloping ST-segment depression in the $V_{1}$ to $V_{6}$ leads, followed by tall and symmetrical $\mathrm{T}$ waves [1], which remain consistent with no evolutionary ECG changes. We present a patient with acute proximal LAD occlusion who presented with an evolutionary ECG change in which the de Winter ST-T changes evolved into ST-segment elevation myocardial infarction (STEMI).

\section{Case presentation}

A 31-year-old male with no medical history presented to the emergency department with persistent chest pain for $1 \mathrm{~h}$. The first ECG (finished in the ambulance) revealed up-sloping ST-segment depression in the $V_{2}$ to $V_{6}$ leads,

\footnotetext{
*Correspondence: wanghao9102@163.com

'Department of Coronary Care Unit, Beijing Royal Integrative Medicine Hospital, No. 1, Wangfu street, Changping District, Beijing 102200, P.R. China Full list of author information is available at the end of the article
}

followed by tall and symmetrical $\mathrm{T}$ waves in the precordial leads, characterized as de Winter ST-T changes (Fig. 1a). The initial troponin I level was $1.48 \mu \mathrm{g} / \mathrm{L}$ (reference range, $0-0.4 \mu \mathrm{g} / \mathrm{L}$ ). The patient received dual loading antiplatelet and statin therapy (aspirin $300 \mathrm{mg}$, ticagrelor $180 \mathrm{mg}$ and rosuvastatin $20 \mathrm{mg}$ ). Thirty minutes later, the arrival ECG showed ST-segment elevation in lead $\mathrm{V}_{2-6}$ (Fig. 1b), and the troponin I level increased to $3.68 \mu \mathrm{g} / \mathrm{L}$. The patient underwent primary percutaneous coronary intervention (PCI), revealing a total occlusion in the proximal LAD (TIMI-0 flow; Fig. 2a) and no stenosis was found in the right or left circumflex coronary arteries. Stent implantation of the LAD artery was performed successfully (Fig. 2b).

\section{Discussion}

Our case illustrated an atypical example of the de Winter ECG pattern subsequently developing into the STEMI pattern due to coronary occlusion. We considered this phenomenon to be related to thrombotic instability in the proximal segment of the LAD. Therefore, we propose that the de Winter ECG pattern should be classified into two 


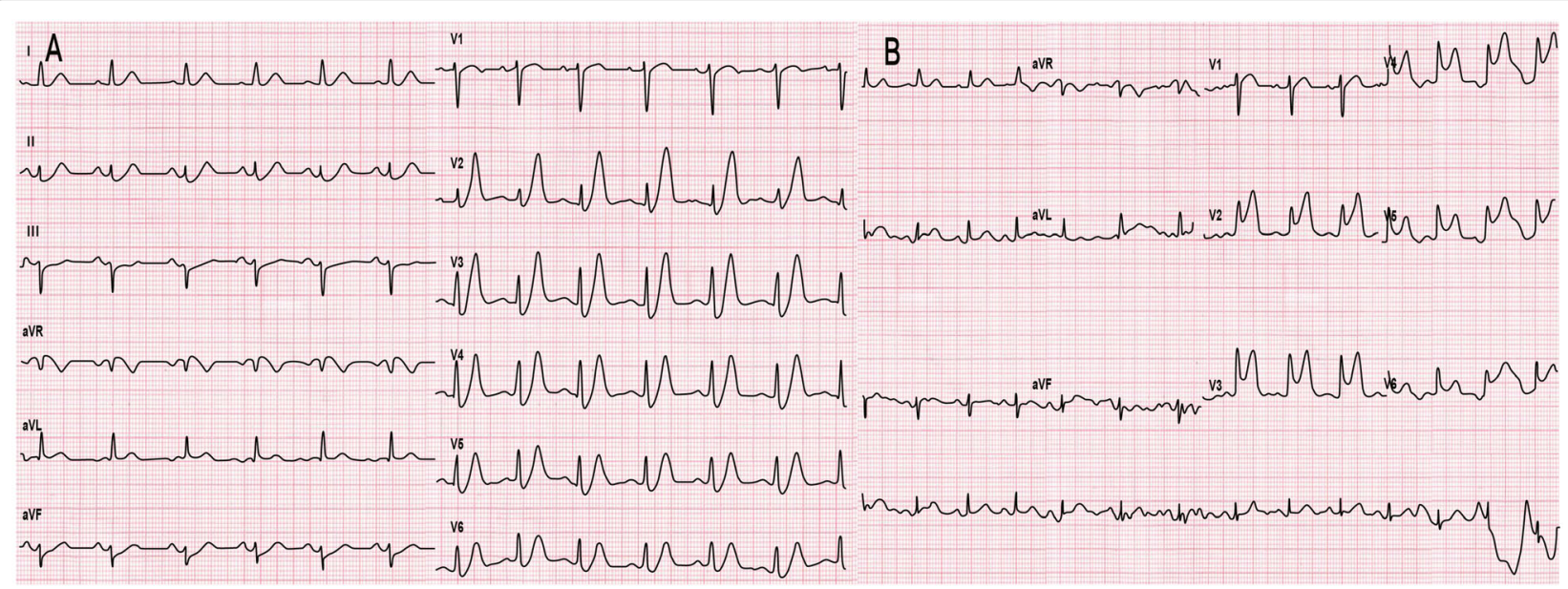

Fig. 1 a The first ECG revealed up-sloping ST-segment depression in the $V_{2}$ to $V_{6}$ leads, followed by tall and symmetrical $T$ waves in the precordial leads; $\mathbf{b}$ the second ECG performed 30 min after admission showed ST-segment elevation in lead $V_{2}$ toV $_{6}$

categories: (1) the static type: a J-point depression persisting until the reperfusion of the LAD with no evolution into STEMI; and (2) the evolutionary ECG change type: a mutual conversion between STEMI and de Winter ST-T changes, which depends on the state of the LAD between complete occlusion and spontaneous recanalization $[2,3]$.

Approximately $2 \%$ of patients with acute subtotal or total occlusion of the proximal LAD artery do not have the usual ST-segment elevation but instead have the de Winter ECG pattern, which was first described as acute subtotal or total proximal LAD occlusion in 2008 in the New England Journal of Medicine [1]. Whether the de Winter ECG pattern can evolve into STEMI is debatable. Fiol Sala first proposed that an evolutionary ECG change between the de Winter ECG pattern and STEMI pattern was due to subtotal or total occlusion of the LAD. When a total occlusion of the anterior descending branch was not treated in a timely manner, it could evolve into
STEMI. In addition, we believe that an evolutionary ST$T$ change in the ECG of patients with a de Winter ECG pattern could lead to a transformation from subtotal LAD occlusion (endocardial ischaemia) to total occlusion (transmural ischaemia), and the latter could cause a change from the de Winter ECG pattern to a STEMI. Therefore, we concur with Fiol Sala et al. that STsegment elevation is possible without the coronary flow restoration $[2,4-6]$.

The lack of activation of sarcolemmal adenosine triphosphate (ATP) sensitive potassium $\left(\mathrm{K}_{\mathrm{ATP}}\right)$ channels was believed to cause the absence of ST-segment elevation in patients [1]. In the hyperacute phase of STEMI, tall, symmetrical $\mathrm{T}$ waves are caused by subendocardial ischaemia. In the acute phase of STEMI, ST-segment elevation is caused by transmural ischaemia [7]. However, the sensitivity to ischaemia is different between endocardium and epicardium, especially the cells at the

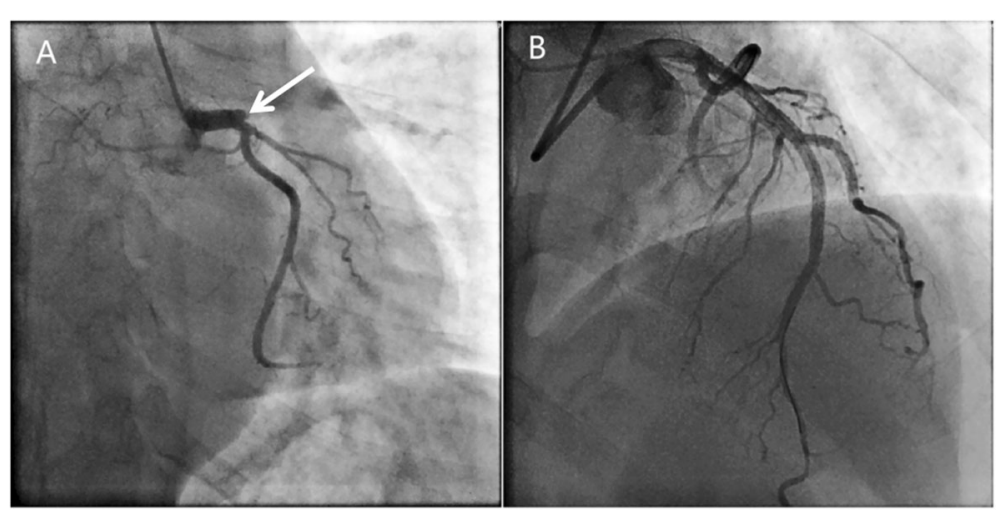

Fig. 2 a Coronary angiogram revealed a total occlusion in the proximal LAD ([white arrowhead]; b The lesion was treated by PCI with one drugeluting stent, showing TIMI-3 flow 
junction between the intermediate myocardium and the endocardium. Hypoxia in the mid-myocardium may be the main cause of ECG manifestation of the de Winter pattern [8].

Some STEMI patients have a severe thrombus burden. Therefore, assessing their admission glucose is necessary because studies have shown that patients with admission hyperglycaemia would have increased mortality even if they underwent primary PCI [9]. One study reported that thrombus burden was associated with a proinflammatory/pro-coagulable state [10]. For these patients, thrombus aspiration (TA) was used to restore blood flow during the primary PCI; however, it was still unclear which type of hyperglyacemic STEMI patients were appropriate for TA [11].

\section{Conclusion}

It is worth emphasizing that, regardless of the evolution of the de Winter ECG pattern, those ECGs represent acute coronary syndrome and should not be overlooked by emergency physicians and cardiologists. Similarly, the de Winter ECG pattern with stenocardia is equivalent to the STEMI pattern that should not be missed in the emergency setting. The evolutionary ECG changes depend on various factors, such as unstable thrombus in the proximal segment of the LAD, thrombus autolysis, and coronary artery recanalization. When the de Winter ECG pattern is observed, coronary recanalization could be necessary in order to open the culprit vessel and prevent the ECG from evolving into STEMI and irreversible myocardial damage.

\section{Abbreviations}

LAD: Left anterior descending; ECG: Electrocardiogram; STEMI: ST-segment elevation myocardial infraction; ATP: Adenosine triphosphate; TA: Thrombus aspiration

\section{Acknowledgements}

Not applicable;

\section{Authors' contributions}

H. W. and X.-H. C. contributed to the writing of paper; X.-C. D. contributed to acquisition of data; Y.-T. Z. revised and ultimately approved the version to be published. All authors have read and approved the manuscript.

\section{Funding}

Not applicable;

\section{Availability of data and materials}

All available information is contained within the present manuscript.

Ethics approval and consent to participate

Not applicable;

\section{Consent for publication}

Written informed consent for publication was obtained from the patient;

\section{Competing interests}

The authors declare that they have no competing interests.

\section{Author details}

Department of Coronary Care Unit, Beijing Royal Integrative Medicine Hospital, No. 1, Wangfu street, Changping District, Beijing 102200, P.R. China. ${ }^{2}$ Department of Cardiology, Affiliated Hospital of Jiaxing University, No.1882 Zhonghuan South Road, Jiaxing, Zhejiang 314000 , P.R. China. ${ }^{3}$ Department of Cardiology, Aerospace Center hospital, 15 Yuquan road, Beijing 100049, P.R. China.

Received: 10 March 2020 Accepted: 2 July 2020

Published online: 06 July 2020

\section{References}

1. de Winter RJ, Verouden NJ, Wellens HJ, Wilde AA. A new ECG sign of proximal LAD occlusion. N Engl J Med. 2008;359(19):2071-3.

2. Montero-Cabezas JM, van der Kley F, Karalis I, Schalij MJ. The "De Winter Pattern" Can Progress to ST-segment Elevation Acute Coronary Syndrome. Response. Revista Espanola De Cardiologia (English ed). 2015;68(11):1043.

3. Zhao YT, Wang L, Yi Z. Evolvement to the de Winter electrocardiographic pattern. Am J Emerg Med. 2016;34(2):330-2.

4. Verouden NJ, Koch KT, Peters RJ, et al. Persistent precordial "hyperacute" Twaves signify proximal left anterior descending artery occlusion. Heart. 2009;95(20):1701-6.

5. Montero-Cabezas JM, van der Kley F, Karalis I, Schalij MJ. Proximal left anterior descending artery acute occlusion with an unusual. electrocardiographic pattern: not everything is ST elevation. Revista Espanola de Cardiologia (English ed). 2015;68(6):541-3.

6. Fiol Sala M, Bayés de Luna A, Carrillo López A, García-Niebla J. The "De Winter pattern" can Progress to ST-segment elevation acute coronary syndrome. Revista Espanola de Cardiologia (English ed.). 2015;68(11):1042-3.

7. Birnbaum $Y$, Bayés de Luna $A$, Fiol $M$, et al. Common pitfalls in the interpretation of electrocardiograms from patients with acute coronary syndromes with narrow QRS: a consensus report. J Electrocardiol. 2012;45(5): 463-75.

8. $\quad \mathrm{Xu}$ J, Wang A, Liu L, Chen Z. The de winter electrocardiogram pattern is a transient electrocardiographic phenomenon that presents at the early stage of ST-segment elevation myocardial infarction. Sep. 2018;41(9):1177-84.

9. Sardu C, Barbieri M, Balestrieri ML, et al. Thrombus aspiration in hyperglycemic ST-elevation myocardial infarction (STEMI) patients: clinical outcomes at 1-year follow-up. Cardiovasc Biabetology. 2018;17(1):152.

10. D'Onofrio N, Sardu C, Paolisso P, et al. MicroRNA-33 and SIRT1 influence the coronary thrombus burden in hyperglycemic STEMI patients. J Cell Physiol. 2020;235(2):1438-52

11. Sardu C, D'Onofrio N, Mauro C, Balestrieri ML, Marfella R. Thrombus Aspiration in Hyperglycemic Patients With High Inflammation Levels in Coronary Thrombus. J Am Coll Cardiol. 2019;73(4):530-1.

\section{Publisher's Note}

Springer Nature remains neutral with regard to jurisdictional claims in published maps and institutional affiliations.
Ready to submit your research? Choose BMC and benefit from:
- fast, convenient online submission
- thorough peer review by experienced researchers in your field
- rapid publication on acceptance
- support for research data, including large and complex data types
- gold Open Access which fosters wider collaboration and increased citations
- maximum visibility for your research: over $100 \mathrm{M}$ website views per year
At BMC, research is always in progress.
Learn more biomedcentral.com/submissions 